\title{
ZETA POTENTIAL STUDY OF THE WATER TREATMENT
}

OF GEOTHERMAL BRINES

\section{MASTER'}
P. M. Wikoff
D. F. Suciu

U.S. Department of Energy

Idaho Operations Office • Idaho National Engineering Laboratory

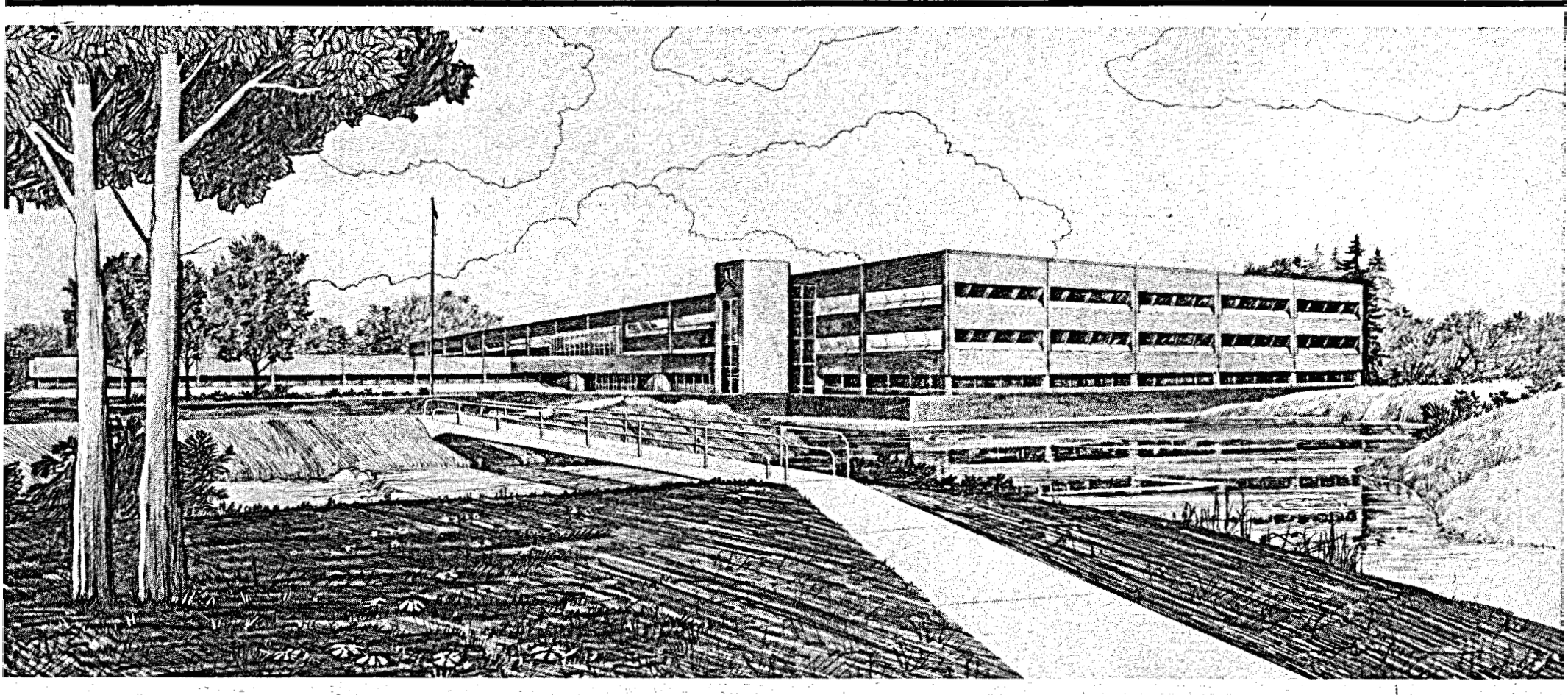

This is an informal report intended for use as a preliminary or working document

Work supported by the U. S. Department

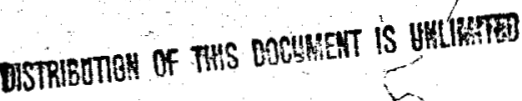
of Energy Assistant Secretany for Resource Application, Office of Geothermal, under DOE Contract No. DE-AC07-76ID01570. 


\section{DISCLAIMER}

This report was prepared as an account of work sponsored by an agency of the United States Government. Neither the United States Government nor any agency Thereof, nor any of their employees, makes any warranty, express or implied, or assumes any legal liability or responsibility for the accuracy, completeness, or usefulness of any information, apparatus, product, or process disclosed, or represents that its use would not infringe privately owned rights. Reference herein to any specific commercial product, process, or service by trade name, trademark, manufacturer, or otherwise does not necessarily constitute or imply its endorsement, recommendation, or favoring by the United States Government or any agency thereof. The views and opinions of authors expressed herein do not necessarily state or reflect those of the United States Government or any agency thereof. 


\section{DISCLAIMER}

Portions of this document may be illegible in electronic image products. Images are produced from the best available original document. 


\section{EGG-GTH- -5673}

DE82 005910

ZETA POTENTIAL STUDY

OF THE WATER TREATMENT OF GEOTHERMAL BRINES

P. M: Wikoff

D. F. Suciu

November 1981

DSTRE 
Before the cooled geothermal fluid can be used as a coolant in the operation of the 5MW(e) Geothermal Pilot Power Plant, the fluid must be treated to reduce the silica and hardness and to control corrosion. Prior to reinjection, the blowdown must be treated to remove the phosphate (one of the corrosion inhibitors added to the system). The zeta potential study was conducted to study the surface reactions occurring in the flash mixing of the cooled geothermal with magnesium oxide, lime, and polyelectrolyte for silica removal and to determine the optimum polyelectrolyte necessary in the silica reduction system and the reduction of the phosphate in the tower blowdown with ferrous sulfate.

The investigation indicates a bridging type adsorption occurs in the silica reduction system. The proposed mechanism is described. The study indicated that between 150 and $250 \mathrm{ppm}$ of magnesium oxide was necessary to achieve this reduction with one ppm of Betz $1125 \mathrm{~L}$. This is a substantial savings over the planned value. Investigation of the phosphate reduction system showed that a cationic polymer was necessary to achieve good flocculation and settling. 


\section{SUMMARY}

Prior to use as a coolant in the operation of the 5MW(e) Geothermal Pilot Power Plant, the cooled geothermal requires a pretreatment process for silica and hardness reduction and a treatment process for corrosion control. The zeta potential studies reported here were conducted to study the surface reactions occurring in the silica reduction system, and to determine the optimum flocculant concentration required for good silica removal. In addition, the optimum flocculant and flocculant concentration was examined for the phosphate reduction system.

The results of the zeta potential study on the silica reduction system suggests adsorption between the magnesium hydroxide formed in solution and the silica. With the addition of calcium ion, there is a bridging type adsorption between the silica-magnesium hydroxide particles. The optimum MgO concentration, added as $\mathrm{MgCl}_{2}$, is between 150 to $250 \mathrm{ppm}$ of $\mathrm{MgO}$. The optimum $\mathrm{pH}$ was 10.2 adjusted with 1 ime. Betz $1125 \mathrm{~L}$ will be the polymer used. The data indicates $1 \mathrm{ppm}$ will result in the maximum silica reduction. An excess of the polymer, $8 \mathrm{ppm}$ or greater, will result in more silica remaining in solution.

The zeta potential study of the phosphate reduction system indicates that the optimum iron concentration lies between 20 and $30 \mathrm{ppm}$ iron added as ferrous sulfate. Optimum pH is 9.2 adjusted with lime. Betz 1195, cationic polymer produced the largest and best settling flocs. The optimum polymer concentration is 2 to $4 \mathrm{ppm}$ of Betz 1195. The data for the phosphate system was obtained for domestic water without the presence of zinc sulfate or dispersants that will be present in the blowdown water. Further optimization will probably be necessary when operating. 
ABSTRACT .............................

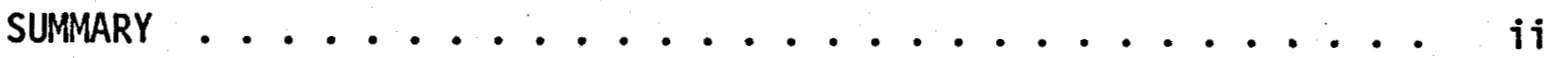

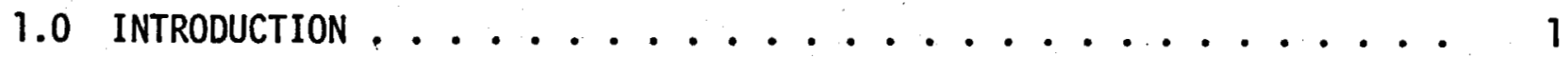

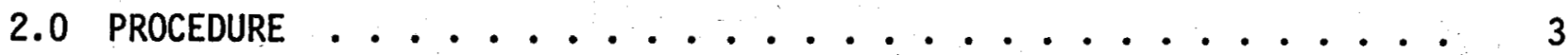

3.0 EXPERIMENTAL RESULTS .................. 5

3.1 Lime Addition Versus Caustic Addition ............ 5

3.2 Calcium Addition Versus Magnesium Addition

(no pH adjustment) ............... 7

3.3 Lime Addition Versus Caustic Addition with

$300 \mathrm{ppm} \mathrm{MgO} \mathrm{(as} \mathrm{MgCl}_{2}$ Present) ........... 7

3.4 Magnesium Oxide Concentration with $\mathrm{pH}$ Adjusted ...... 11

3.5 Calcium Addition in the Presence of $\mathrm{MgO}$

(with and without $\mathrm{pH}$ adjustment) ............ 11

3.6 Polyelectrolyte Addition ................. 11

3.7 Phosphate Removal from the Tower Blowdown .......... 15

4.0 DISCUSSION AND CONCLUSIONS ........................ 19

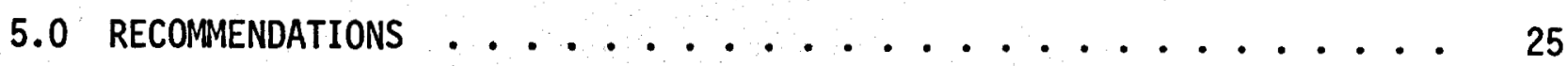

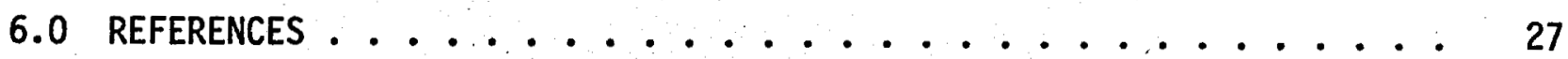

FIGURES

1. Theoretical Zeta Potential Curve .............. 4

2. Zeta Potential Versus $\mathrm{pH}$ with Lime or Caustic Addition ....... 6

3. Zeta Potential Versus Calcium or Magnesium Concentration

with No pH Adjustment .................. 8

4. Zeta Potential and Silica Concentration Versus $\mathrm{pH}$ with Lime

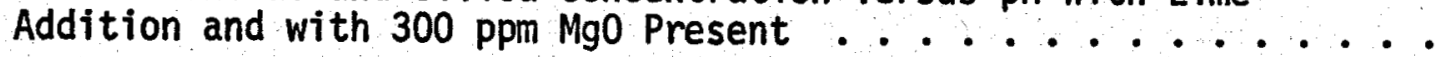

5. Zetz Potential Versus $\mathrm{pH}$ with Caustic Addition with $300 \mathrm{ppm}$ Mg0 Present

6. Zeta Potential and Silica Concentration Versus the Magnesium Oxide Concentration with the $\mathrm{pH}$ Adjusted with Lime .........

7. Zeta Potential and Silica Concentration as a Function of Calcium Addition in the Presence of $300 \mathrm{ppm} \mathrm{MgO}$ 


\section{FIGURES}

(Cont'd)

8. Zeta Potential and Silica Concentration as a Function of

9. Zeta Potential and Phosphate Concentration of the Tower Blowdown as a Function of Iron Concentration .......... 16

10. Zeta Potential of the Iron-Phosphate System as a Function of $\mathrm{pH} \ldots \ldots \ldots \ldots 17$

11. Zeta Potential and Phosphate Concentration of the IronPhosphate System as a Function of Betz 1125L Concentration ... . . 18

12. Zeta Potential of the Iron-Phosphate System as a Function of Cationic Polymer ................... 20

13. Zeta Potential of the Iron-Phosphate System with $2 \mathrm{ppm}$ Betz 1195 as a Function of $\mathrm{pH} \ldots \ldots 21$

14. Zeta Potential of the Iron-Phosphate System at $\mathrm{pH} 9.2$ as a Function of Betz 1195 concentration ............ 22

15. Total and Ortho Phosphate Remaining in the Solution at $\mathrm{pH} 9.2$ as a Function of Betz 1195 Concentration ......... 23

\section{TABLES}

1. Stability Characterisitcs as a Function of Zetz Potential ..... 2

2. Comparison of Cost with Required Mg0 Concentration ........ 25

3. Comparison of Cost with Required Polyelectrolyte Concentration 


\subsection{INTRODUCTION}

Due to the location, the operation of the 5MW(e) Geothermal Pilot Power Plant requires the use of cooled geothermal water as a coolant to circulate between the condenser and the wet (open-loop, evaporative) cooling tower. The system requires a pretreatment process for silica and hardness reduction and a treatment process for corrosion control.

In the pretreatment process, as established by Suciu and Miller ${ }^{1}$, the cooled geothermal water is flash mixed with $\mathrm{MgCl}_{2}$ and lime ( $\mathrm{pH}$ 10.2) for silica removal. Soda ash is added to reduce the hardness. After flash mixing, Betz $1125 \mathrm{~L}$ (a coagulating aid) is added to enhance flocculation. In the corrosion treatment system, phosphate is used as one of the corrosion inhibitors. Before reinjection, the blowdown will be treated with ferrous sulfate for phosphate removal. Polyelectrolyte will again be added to enhance flocculation.

The zeta potential study was established in order to study the surface reactions occurring in the silica removal system and to determine the optimum concentration of flocculant necessary for good silica and phosphate removal.

All particles in solution have a net surface charge (either positive or negative). Other ions in the solution tend to adsorb at the surface of these particles due to chemical, electrostatic, or physical adsorption. At the surface of the particle there is, therefore, one or more layers of charged ions. These layers become more diffuse as the distance from the particle increases. The zeta potential is the difference between the charge of the diffuse layer and the bulk solution. ${ }^{2}$ In order to determine the zeta potential, a potential gradient is set up in a solution of charged particles and the rate of motion of the particles is measured. The zeta potential is proportional to the rate of motion and can be calculated by the Helmholtz Smoluchowski equation. ${ }^{3}$

The zeta potential or surface charge can be controlled through the addition of certain electrolytes or polyelectrolytes which adsorb onto the surface due to one of the following mechanisms: electrostatic adsorption, 
physical adsorption, or chemical adsorption. Electrostatic adsorption results from the electrostatic attraction between the electrolyte and charged particle. These occur due to opposite charges. Simple electrostatic adsorption does not produce major changes in the zeta potential. 4 Physical adsorption occurs due to van der Waal and/or Coulombic forces such as occur when like particles interact. In general, physical adsorption causes, as does electrostatic adsorption, little change in the zeta potential. Chemical adsorption, being a much stronger adsorption, causes the greatest zeta potential change. Chemical adsorption can be due to ion exchange type reactions or the formation of salt type minerals. In many cases physical or electrostatic adsorption can result in chemical adsorption.

Through a zeta potential study the mechanism of the surface reactions can be postulated and recommendations made concerning flocculation. One cannot state categorically that a colloid will be stable at a certain zeta potential, but the general rule for determining coagulation according to the zeta potential can be summarized according to Table 1 below. ${ }^{5}$

TABLE 1. STABILITY CHARACTERISTICS AS A FUNCTION OF ZETA POTENTIAL

\section{Stability Characteristics}

Maximum agglomeration and precipitation

Excellent agglomeration and precipitation

Fair agglomeration and precipitation

Threshold of agglomeration (agglomerates

of 2 to 10 colloids)

Plateau of slight stability (few agglomerates)

Moderate stability (no agglomerates)
Average ZP

Millivolts

+3 to zero

-1 to -4

-5 to -10

-11 to -20

-21 to -30

-31 to -40

-41 to -50

-51 to -60

-61 to -80

-81 to -125 
Figure 1 shows a theoretical curve in which zeta potential is plotted as a function of the $\mathrm{pH}$ of the system. In addition, the silica remaining in the system after flocculation and settling has occurred is plotted as a function of $\mathrm{pH}$. Looking at only the zeta potential curve, the area where good flocculation should occur is determined by the $\mathrm{pH}$ 's at which the zeta potential curve intersects the $-10 \mathrm{mV}$ and $+10 \mathrm{mV}$ lines. In this case, the area lies between $\mathrm{pH} 9.8$ and 10.7. The silica versus $\mathrm{pH}$ curve shows that between pH 9.8 and $\mathrm{pH} 10.7$ the silica has decreased to its low concentration and remains essentially constant.

In the following pages, experimental procedures and results of the zeta potential study are discussed as well as conclusions and recomendations resulting from the study.

\subsection{PROCEDURE}

Unless otherwise stated, the water used was Raft River geothermal at $60^{\circ} \mathrm{C}$. The desired reagents were added. The solution was stirred at 120 RPM for 2 minutes and 20 RPM for 15 minutes. The zeta potential (particle motion) was measured using a Unitron Zeta Meter at $4 X$ magnification using the optimum voltage designated by the conductivity of the solution. The conductivity was recorded for each test as was temperature and rate of motion. Tests were run to determine zeta potential of each step of the treatment processes for silica and phosphate removal.

The zeta potential was determined using the graphs provided with the zeta meter. 5 The use of these graphs assume a viscosity and dielectric constant close to that for distilled water. Although this may or may not be true for the geothermal system, it is reasonable that there should be little or no change in these values among the solutions used in these zeta potential determinations. Since the work involves comparison of values, the graphs should be a good indication of what is happening. 


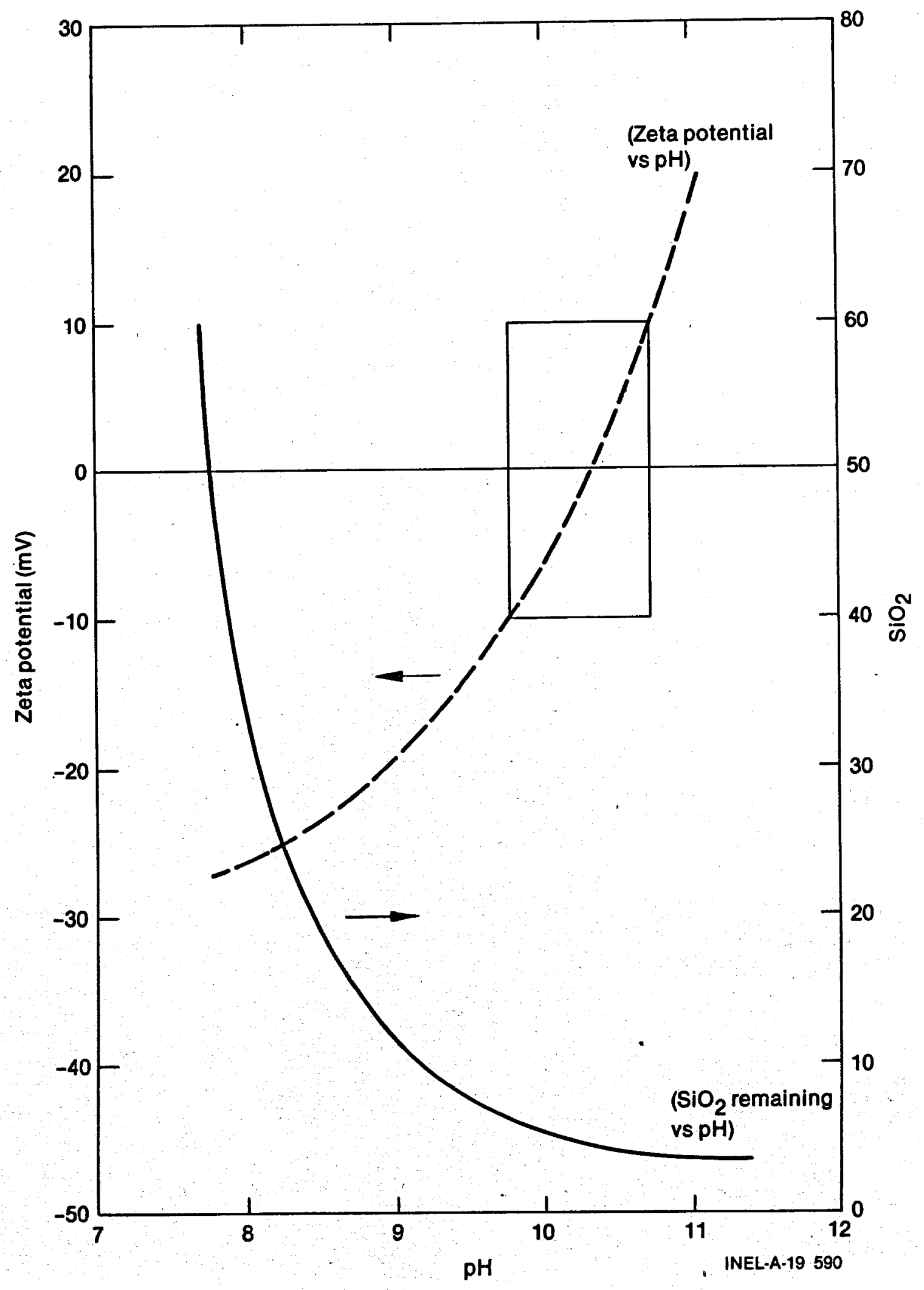

Figure 1. Theoretical Zeta Potential Curve 


\subsection{EXPERIMENTAL RESULTS}

In order to check the zeta meter and the procedure for measuring the zeta potential, the zeta potential for Minusil was determined. Minusil is a natural silica produced by crushing sandstone. Minusil maintains a constant zeta potential of $-55 \pm 2 \mathrm{mV}$ when suspended at $100 \mathrm{ppm}$ in $100 \mathrm{ppm}$ $\mathrm{NaCl}$. With this suspension, a zeta potential of $-56 \mathrm{mV}$ was obtained.

The series of zeta potential studies performed on the geothermal fluid can be grouped into seven groups:

1. Zeta potential as a function of lime addition versus caustic addition.

2. Zeta potential as a function of calcium $\left(\mathrm{CaCl}_{2}\right)$ addition versus magnesium $\left(\mathrm{MgCl}_{2}\right)$ addition with no $\mathrm{pH}$ adjustment.

3. Zeta potential with $300 \mathrm{ppm} \mathrm{MgO}\left(\mathrm{MgCl}_{2}\right)$ as a function of 1 ime addition versus caustic addition.

4. Zeta potential with $300 \mathrm{ppm} \mathrm{MgO}\left(\mathrm{MgCl}_{2}\right)$ present with and without $\mathrm{pH}$ adjustment as a function of calcium $\left(\mathrm{CaCl}_{2}\right)$ addition.

5. Zeta potential as a function of $\mathrm{MgO}\left(\mathrm{MgCl}_{2}\right)$ concentration with pH adjustment.

6. Zeta ptential as a function of Betz $1125 \mathrm{~L}$ concentration.

7. Zeta potential study of the phosphate removal system.

\subsection{Lime Addition Versus Caustic Addition}

There is a positive increase $(20 \mathrm{mV})$ in the zeta potential (Figure 2) initially with the addition of caustic. After this increase, there is little change in the zeta potential. The small change is probably due to electrostatic adsorption of sodium onto the negative silica. Adsorption is minimal, howeyer. 


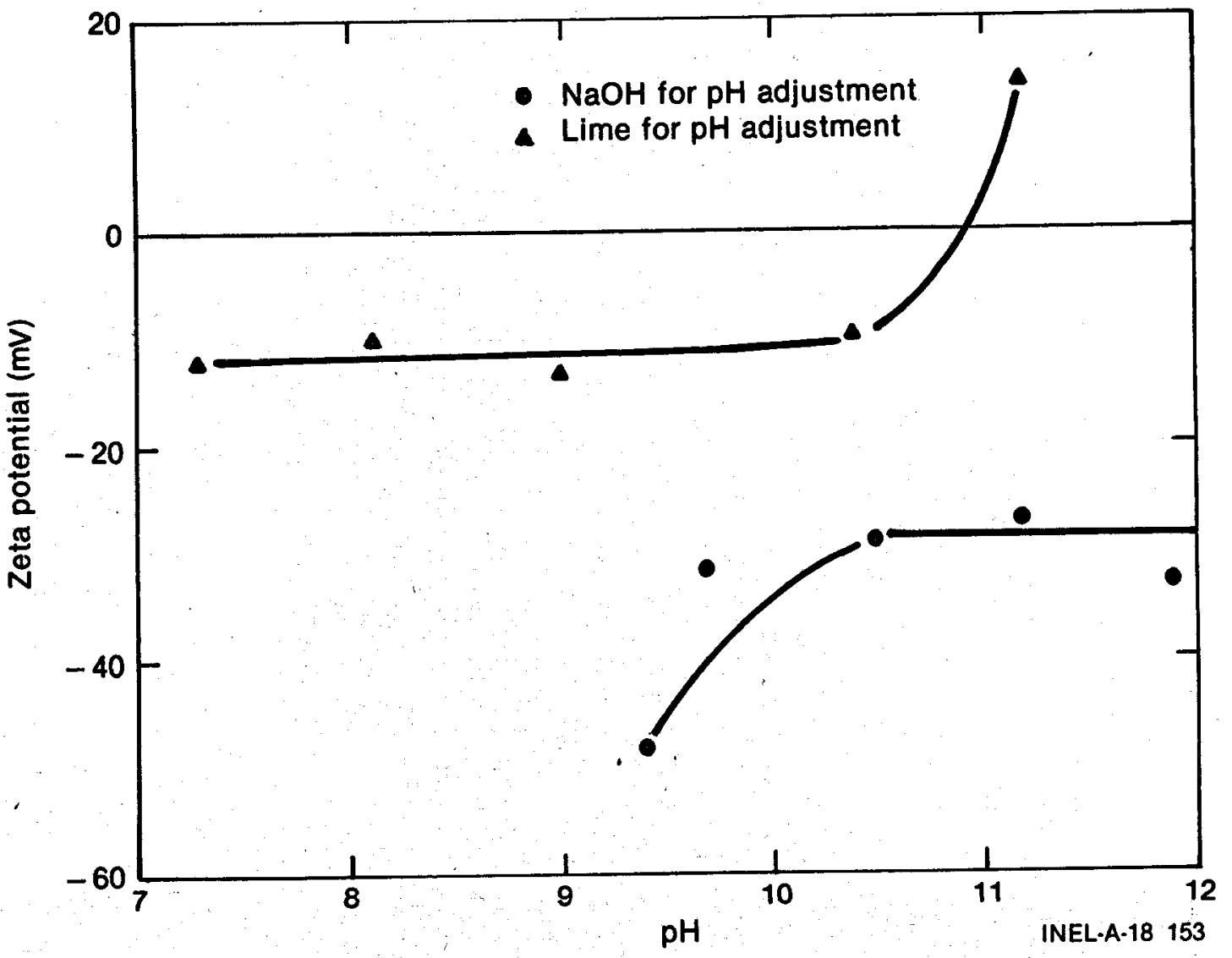

Figure 2. Zeta Potential Versus $\mathrm{pH}$ with Lime or Caustic Addition 
With lime addition the zeta potential was linear and negative until a $\mathrm{pH}$ of 10.4. At this time, the zeta potential increases from -10 millivolts to +14 millivolts between $\mathrm{pH} 10.4$ and 11.2. This large increase in charge with the curve passing through the point of zero charge (ZPC - point at which the surface is electrically neutral) shows at least electrostatic adsorption of the positive calcium and probably is an indication of the chemisorption of the calcium.

\subsection{Calcium Addition Versus Magnesium Addition (no pH adjustment)}

With both magnesium (as magnesium chloride) and calcium (as calcium chloride) addition to the geothermal water without $\mathrm{pH}$ adjustment, there is no major change in the zeta potential (Figure 3 ). With magnesium, the zeta potential passes through a minimum before approaching $-20 \mathrm{mV}$ again. With calcium addition, the zeta potential approaches $-20 \mathrm{mV}$. Both curves show a lot of scatter in the data.

\subsection{Lime Addition Versus Caustic Addition with $300 \mathrm{ppm} \mathrm{MgO}$ (as $\mathrm{MgCl}_{2}$ Present)}

Three hundred $\mathrm{ppm}$ of $\mathrm{MgO}\left(\mathrm{MgCl}_{2}\right)$ was added to the geothermal fluid, and the system was treated with lime for $\mathrm{pH}$ adjustment. Initially there was little change in the zeta potential, then a linear increase from -10 to +44 $\mathrm{mV}$ (Figure 4). Chemical adsorption is occurring. Silica concentration decreases linearly from 150 to $4 \mathrm{ppm} \mathrm{SiO}_{2}$. The reduction to $4 \mathrm{ppm}$ occurs where the zeta potential is approaching zero. There is no increase in the silica concentration, however, as the zeta potential approaches $+40 \mathrm{mV}$ probably due to the nature of the electrolyte $\left(\mathrm{MgCl}_{2}\right)$ added to the system.

With caustic for pH adjustment (Figure 5 ) there is a linear decrease in the zeta potential from -20 to $-60 \mathrm{mV}$ between $\mathrm{pH} 8.5$ and 10.5 due to the adsorption of the hydroxide onto the silica magnesium particle. The silica concentration was not determined due to the lack of sufficient coagulation. 


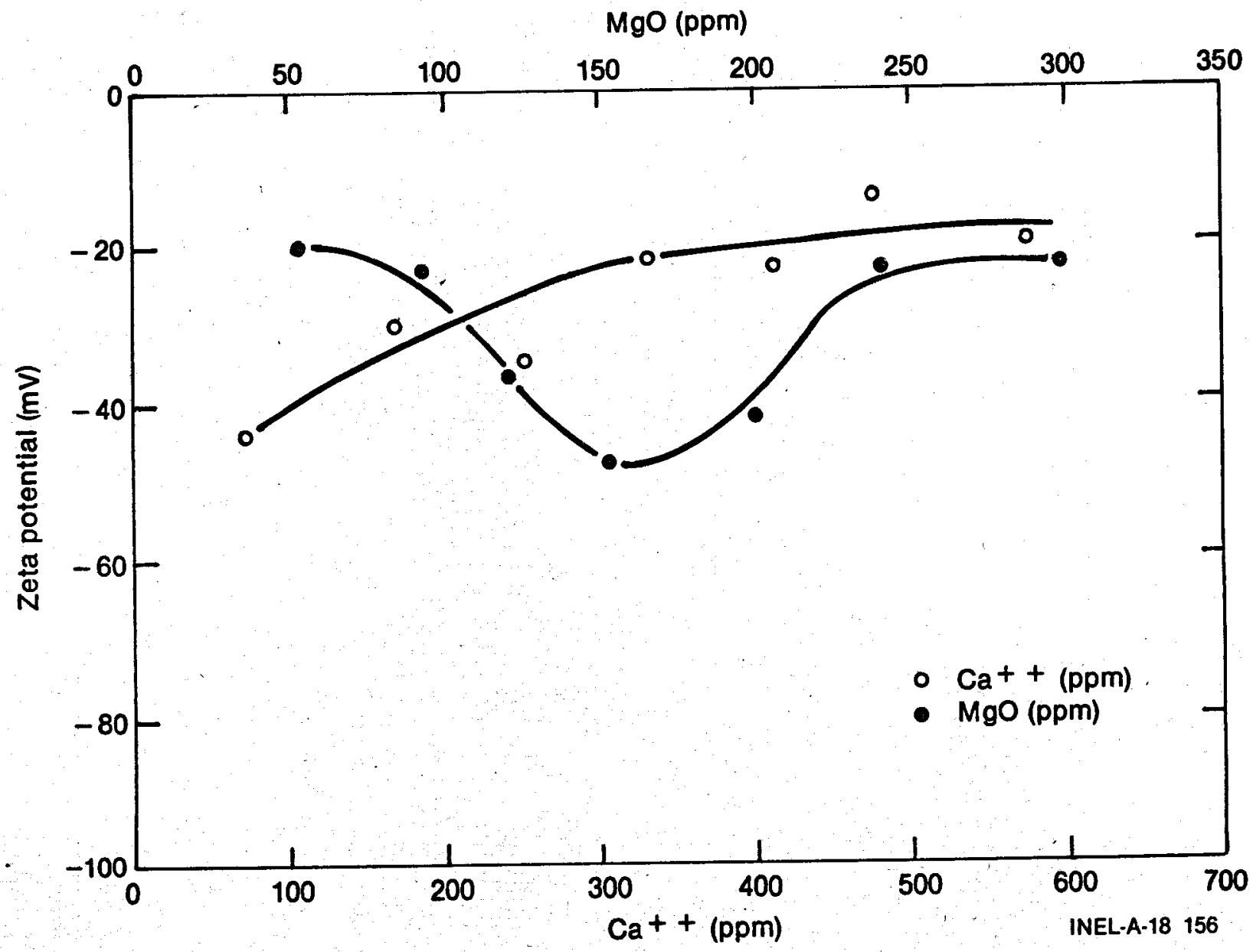

Figure 3. Zeta Potential Versus Calcium or Magnesium Concentration with No pH Adjustment 


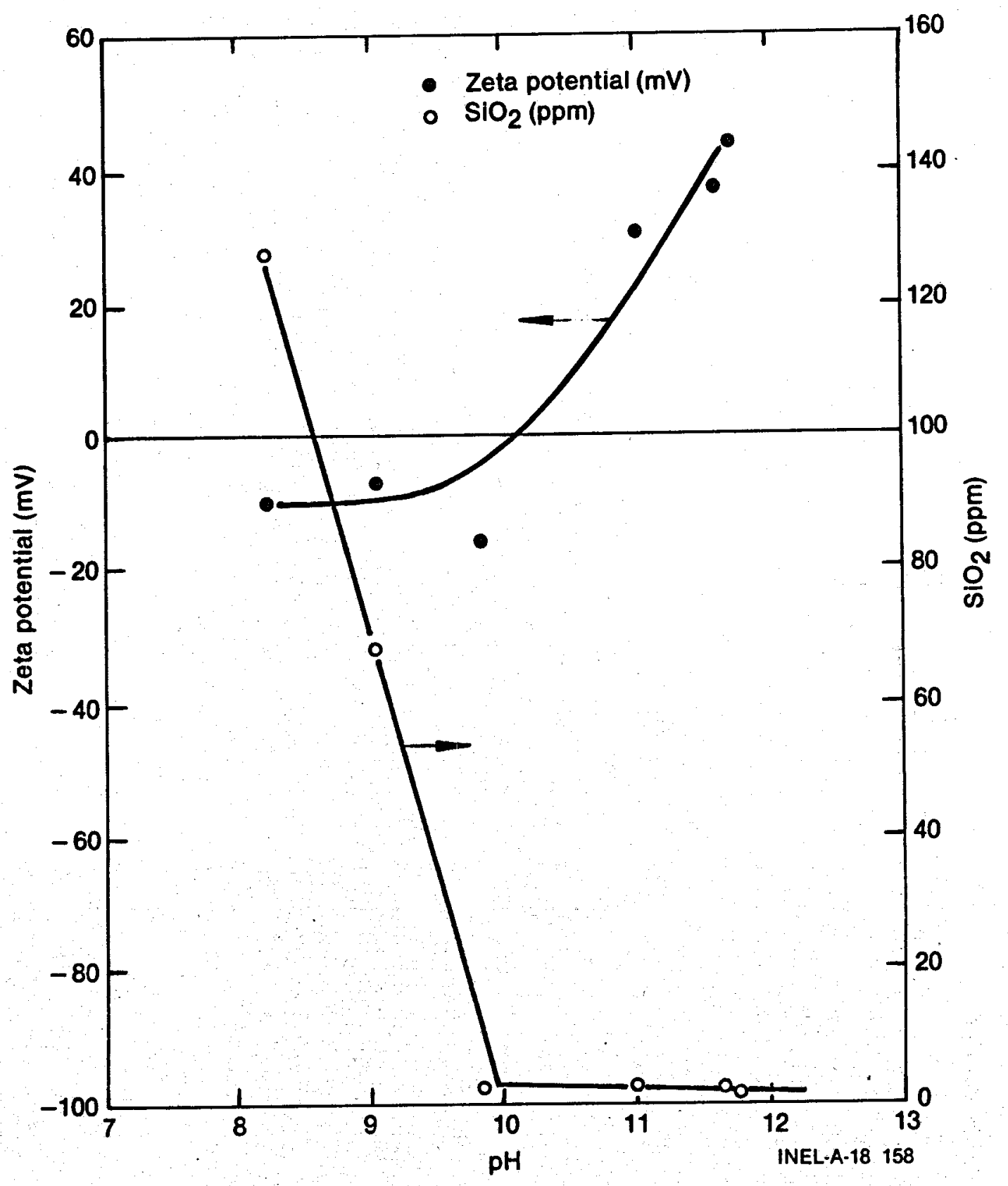

Figure 4. Zeta Potential Versus pH With Caustic Addition with $300 \mathrm{ppm}$ MgO Present 


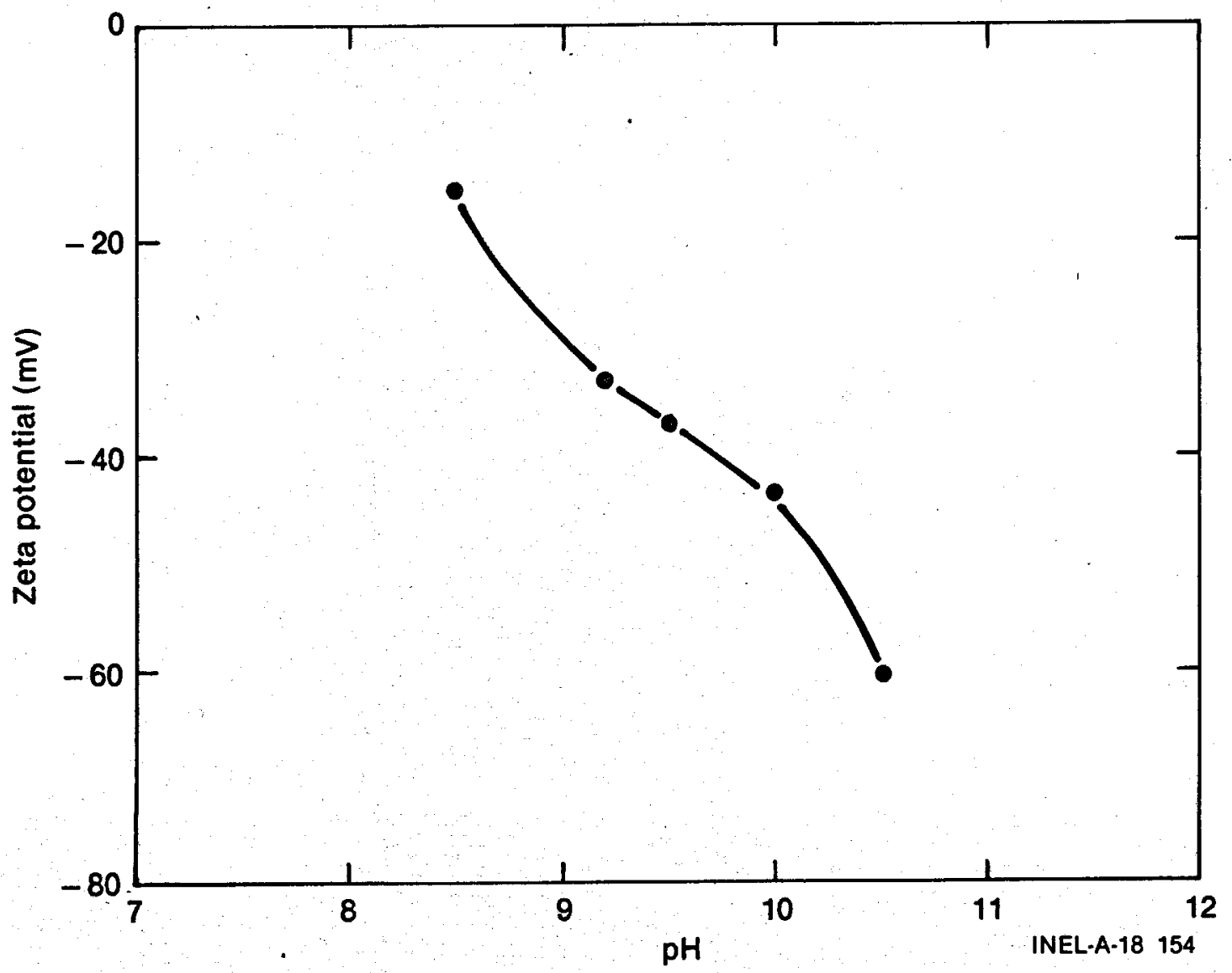

Figure 5. Zeta Potential Versus pH With Caustic Addition with $300 \mathrm{ppm}$ MgO Present 


\subsection{Magnesium Oxide Concentration with $\mathrm{pH}$ Adjusted}

The zeta potential increased exponentially with Mg0 addition when the pH was adjusted to 10.2 with lime (Figure 6) passing through the ZPC at $210 \mathrm{ppm} \mathrm{Mg0}$. The silica levels out between 180 and $250 \mathrm{ppm} \mathrm{MgO.} \mathrm{The}$ increase from -28 to $+11 \mathrm{mV}$ and the change in sign indicates chemical adsorption is occurring.

\subsection{Calcium Addition in the Presence of $\mathrm{MgO}$ (with and without $\mathrm{pH}$ adjustment)}

Without $\mathrm{pH}$ adjustment (Figure 7) the zeta potential curve as a function of calcium $\left(\mathrm{CaCl}_{2}\right)$ concentration with $300 \mathrm{ppm} \mathrm{MgO}$ present looks similar to the one for calcium without Mg0 present. Some adsorption (electrostatic) is . taking place but little change is occurring in the surface properties of the silica. The silica concentration was not decreased to any significant extent. When the $\mathrm{pH}$ is adjusted to 10.2 with caustic, there is a large change in the zeta potential from -73 millivolts to +39 millivolts with the addition of 200 $\mathrm{ppm} \mathrm{Ca}++$ as calcium chloride. The silica decreases to $2.4 \mathrm{ppm} \mathrm{SiO}_{2}$ (Figure 7).

As a further check of the mechanism of adsorption the zeta potential was measured for magnesium oxide, added as magnesium chloride to deionized water, as a function of $\mathrm{pH}$. The $\mathrm{pH}$ was adjusted with lime. The zeta potential shows a general trend to become more negative. Because lack of sufficient coagulation made the zeta potential measurement difficult, too few points were obtained for a zeta potential-pH curve.

\subsection{Polyelectrolyte Addition}

In order to determine the optimum polyelectrolyte necessary to coagulate the silica, the zeta potential was determined as a function of polyelectrolyte (Betz 1125L) concentration. Geothermal water was flash mixed with $300 \mathrm{ppm} \mathrm{MgO}$ (added as $\mathrm{MgCl}_{2}$ ) and lime to $\mathrm{pH} \mathrm{10.3.} \mathrm{The}$ polyelectrolyte was added as a $0.2 \mathrm{w} / 0$ solution to the slurry and stirred 15 minutes. The zeta potential decreases exponentially from +33 millivolts to -70 millivolts at $20 \mathrm{ppm}$ due to the adsorption of the anionic polyelectrolyte (Figure 8 ). The silica remains at its lowest level between 


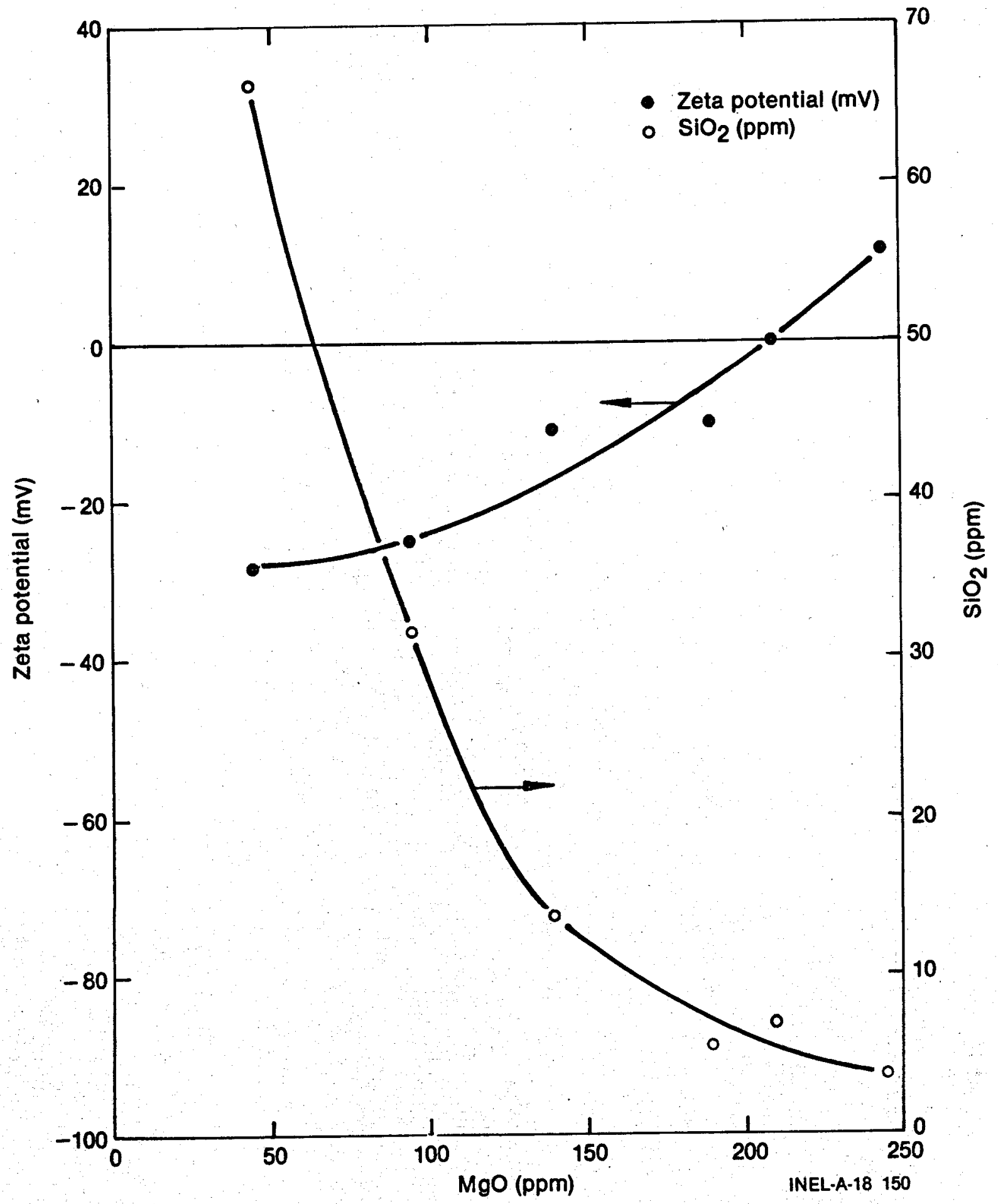

Figure 6. Zeta Potential and Silica Concentration Versus Magnesium Oxide Concentration with $\mathrm{pH}$ Adjusted to 10.2 with Lime 


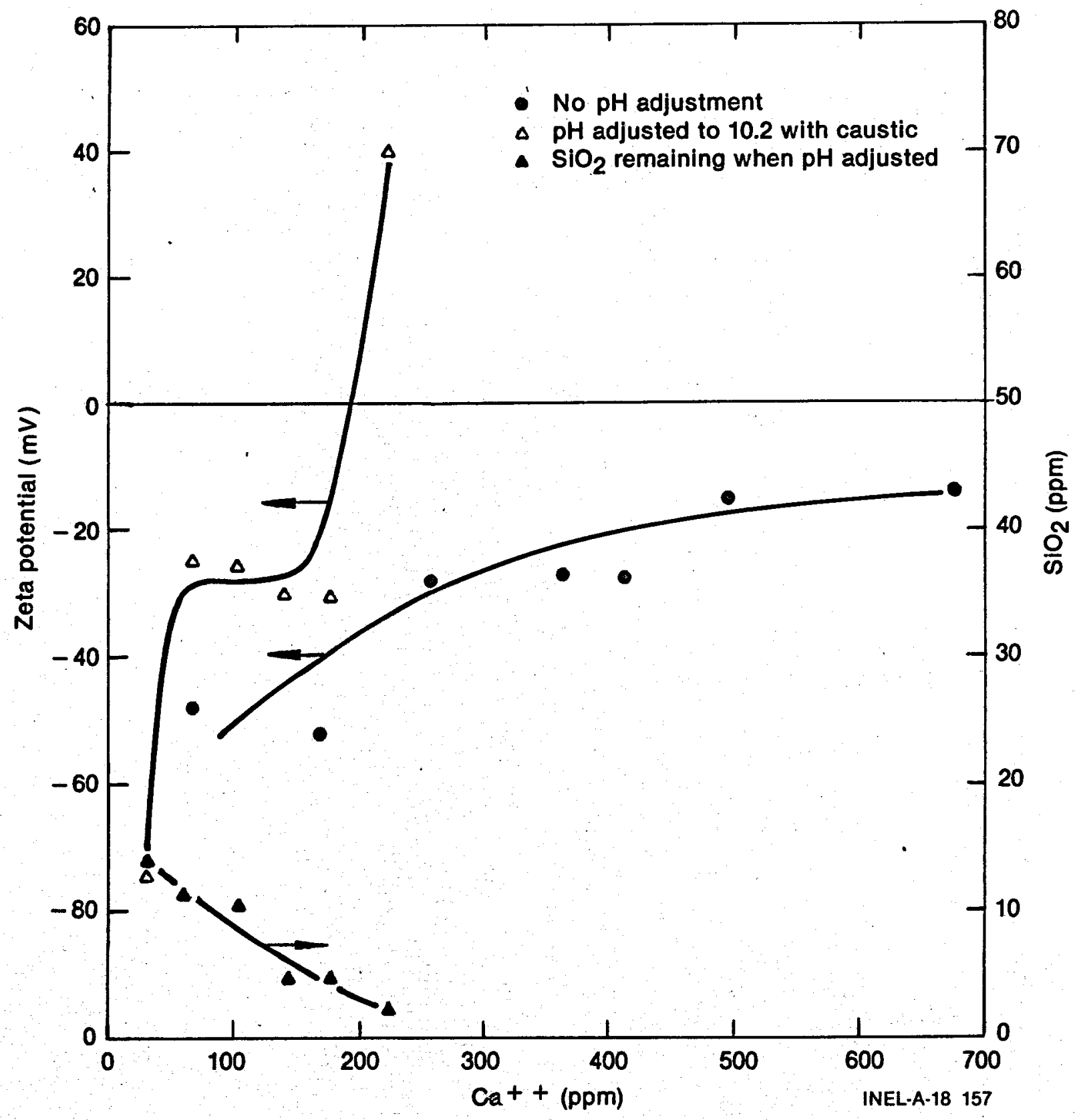

Figure 7. Zeta Potential and Silica Concentration as a Function of Calcium (as $\mathrm{CaCl}_{2}$ ) Addition in the Presence of $300 \mathrm{ppm} \mathrm{Mg0}$ 


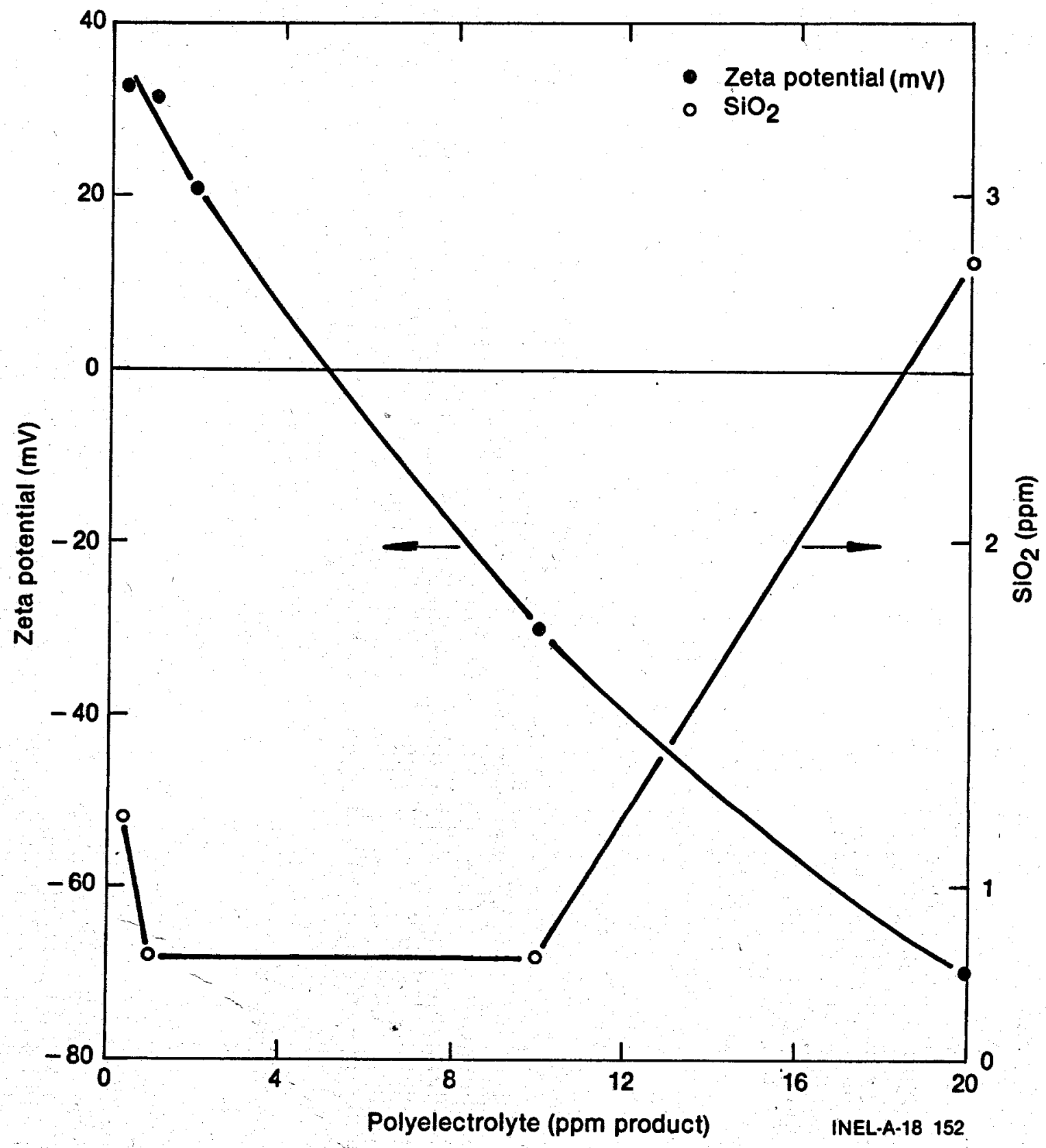

Figure 8. Zeta Potential and Silica Concentration as a Function of Betz 1125L Concentration 
one and eight ppm. With additional polyelectrolyte, the silica increases again. This agrees with Slater, et al., "In large doses the polyelectrolytes act as protective colloids.. Their action as flocculants is confined to very low concentrations." Even with $0.2 \mathrm{ppm}$ of polyelectrolyte, the silica concentration, $1.2 \mathrm{ppm} \mathrm{SiO}_{2}$, is lower than without electrolyte addition. Duplication of the work showed that at $8 \mathrm{ppm}$ of polyelectrolyte, there was a tendency toward much higher silica levels and variations in the zeta potential.

\subsection{Phosphate Removal From the Tower Blowdown}

In the zeta potential study of the phosphate removal system, $500 \mathrm{ml}$ of tower blowdown was adjusted to $40 \mathrm{ppm}$ total phosphate with Betz 35-A (a Betz product having $35 \mathrm{w} / 0$ total phosphate). Ferrous sulfate was added to the system, and the $\mathrm{pH}$ was adjusted to 10.2. The zeta potential was determined as a function of the iron concentration. With this system, there was little change in the zeta potential; however, the zeta potential did go to zero between 30 and $38 \mathrm{ppm}$ of Fett and remained there (Figure 9). Total phosphate tended to level off between 20 and $30 \mathrm{ppm} \mathrm{Fe}$, indicating this is the optimum iron concentration for phosphate removal. However, at this concentration the particle is negative.

Betz 1125L, an anionic polyelectrolyte, was recommended as a flocculation aid for the phosphate reduction system of the $5 \mathrm{MW}(\mathrm{e})$ Geothermal Pilot Power Plant. For successful use of an anionic flocculant, the particle must be positive. In order to determine the $\mathrm{pH}$ at which the iron-phosphate particle becomes positive, $40 \mathrm{ppm}$ of phosphate (Betz $35-\mathrm{A}$ ) and $30 \mathrm{ppm}$ iron (ferrous sulfate) was added to domestic water. The $\mathrm{pH}$ was adjusted with lime. Figure 10 shows that the zeta potential does not pass through zero until $\mathrm{pH} 11.5$. An additional test was conducted to determine the efficiency of Betz $1125 \mathrm{~L}$ at $\mathrm{pH} 11.0$ and 11.7, using the above concentrations of iron and phosphate. The zeta potential was determined as a function of the concentration of polymer added (Figure 11). Much better phosphate reduction was obtained at $\mathrm{pH}$ 11.7, where the particle was positive. The optimum reduction occurred at 1 to $2 \mathrm{ppm}$ of the polymer. Such a high $\mathrm{pH}$, however, is costly. 


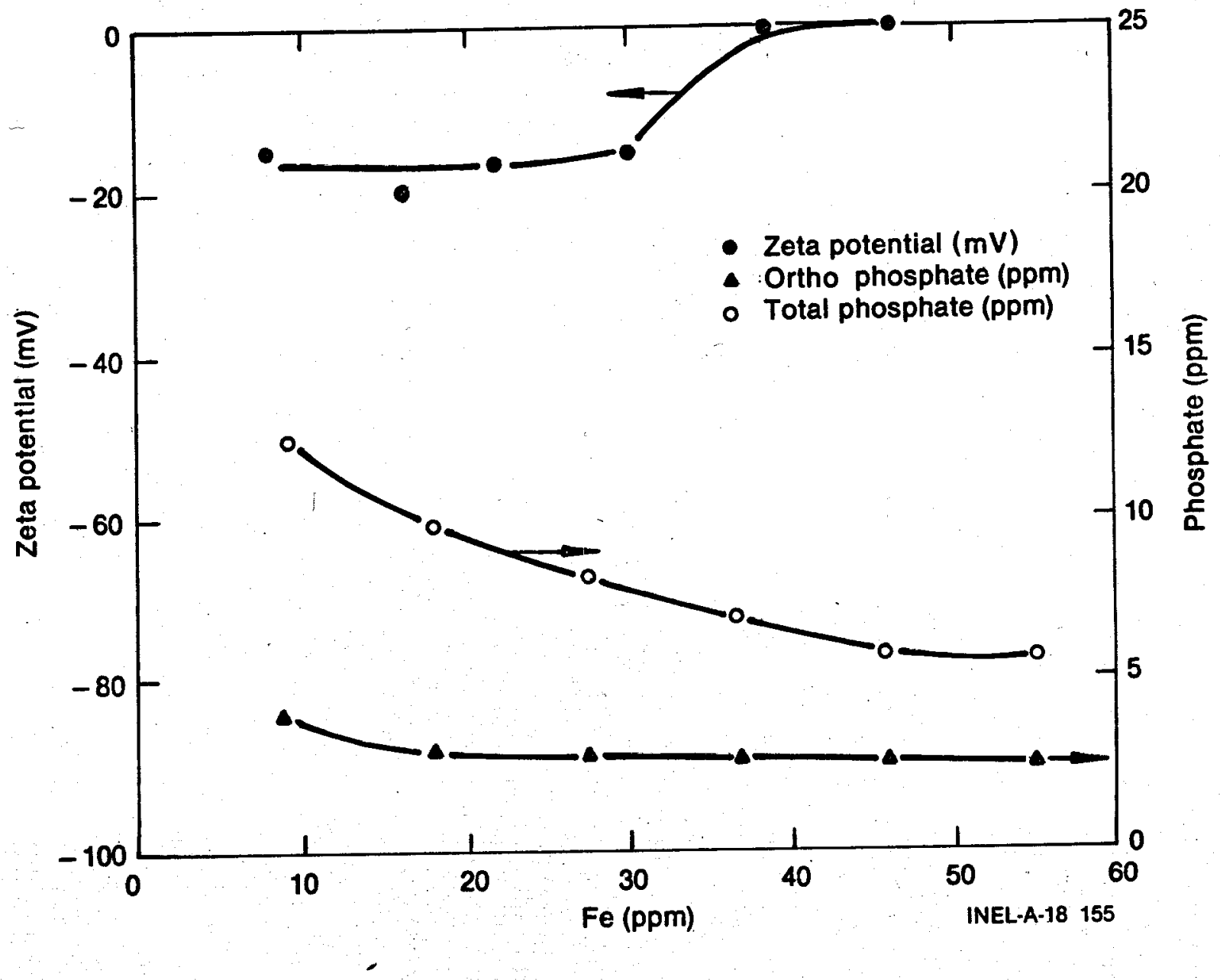

Figure 9. Zeta Potential and Phosphate Concentration of the Tower Blowdown as a Function of Iron Concentration 


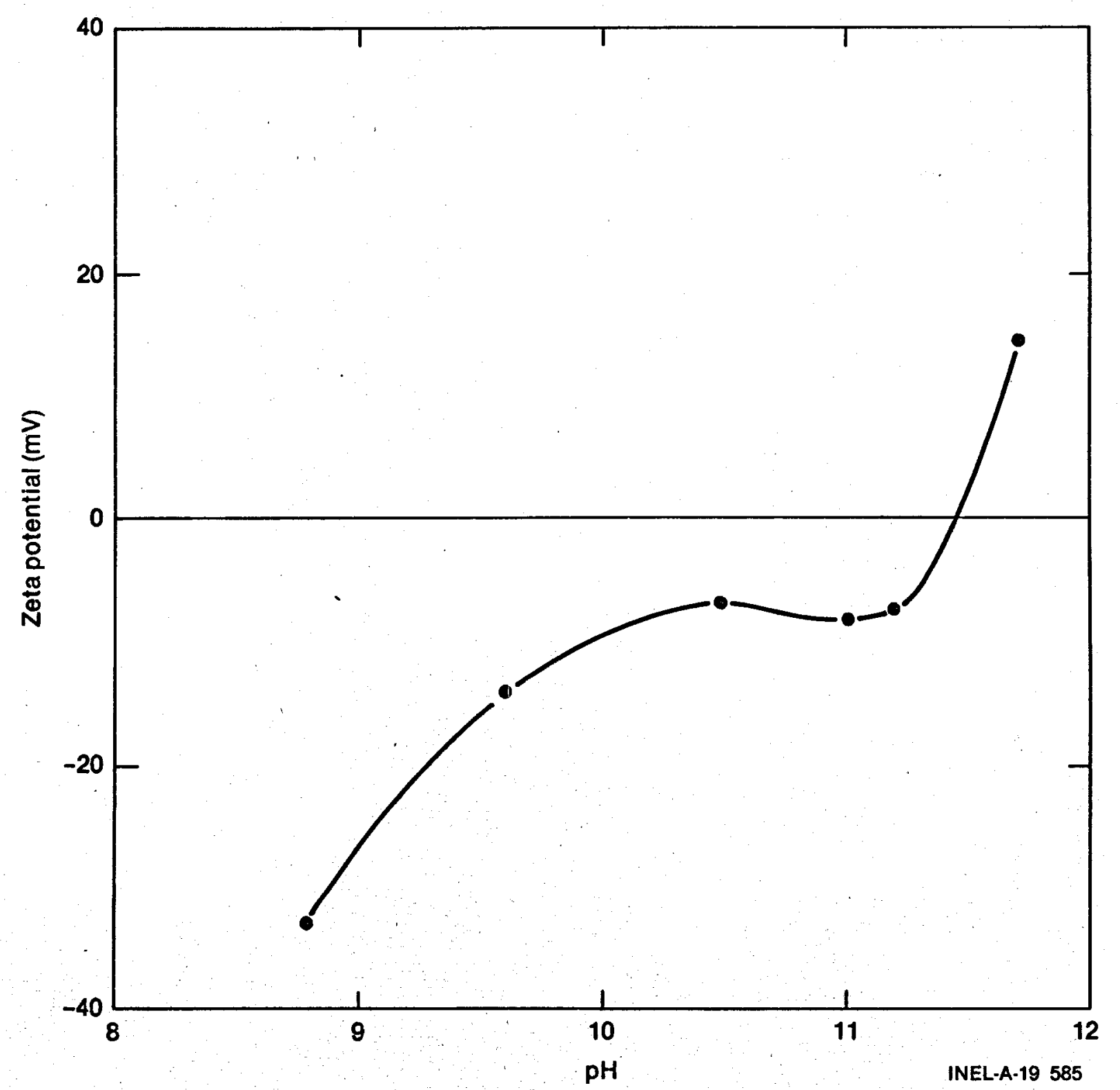

Figure 10. Zeta Potential of the Iron-Phosphate System as a Function of $\mathrm{pH}$ 


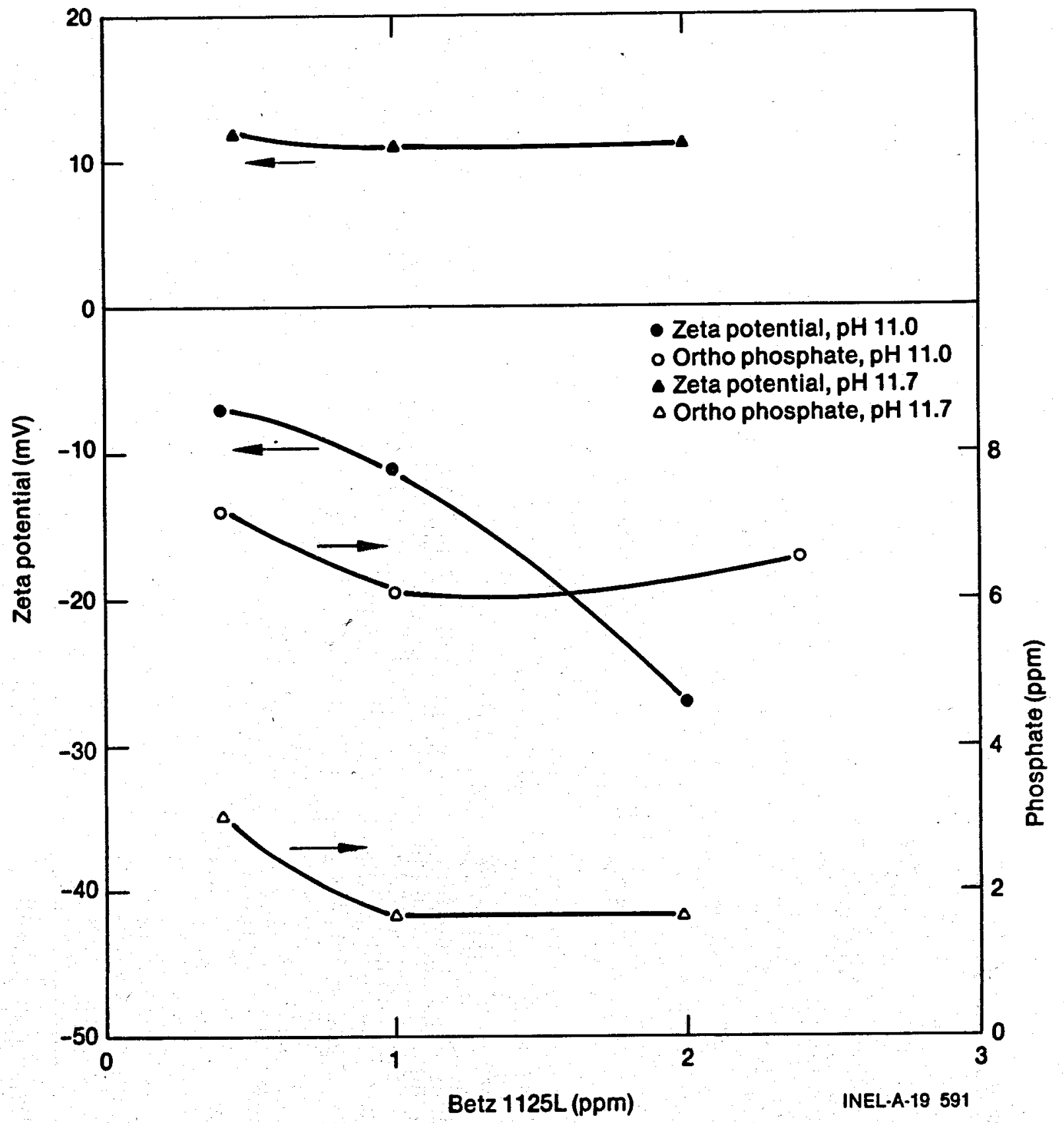

Figure 11. Zeta Potential and Phosphate Concentration of the Iron-Phosphate System as a Function of $\mathrm{pH}$ and Betz 1125L Concentration 
The zeta potential of the iron-phosphate system was examined at $\mathrm{pH} \mathrm{9,}$ using several Betz cationic polymers as a function of polymer concentration. The results are shown in Figure 12. The zeta potential curve for 1175 and 1185 remains negative from 0.2 to $10 \mathrm{ppm}$ of the polymers. The floc was extremely fine and slow settling. Use of three of the polymers caused the system to become positive. However, the zeta potential curves for the 1180 and 1190 show very little range at which good flocculation should occur. Betz 1195 shows a more stable curve passing through zero to $+6 \mathrm{mV}$ then remaining zero along the remainder of the concentration range to $10 \mathrm{ppm}$. In all cases, the 1195 resulted in the formation of large flocs and good settling.

A zeta potential curve as a function of $\mathrm{pH}$ using $2 \mathrm{ppm}$ of Betz 1195 and lime for $\mathrm{pH}$ adjustment in the iron-phosphate system (Figure 13) indicates the zeta potential passes through zero near a $\mathrm{pH}$ of 9.1 or 9.2. Using $\mathrm{pH}$ 9.2, the zeta potential of the iron phosphate system was determined as a function of 1195 concentration. Figure 14 shows the zeta potential passes through zero at about $3.0 \mathrm{ppm} 1195$ and reaches $+10 \mathrm{mV}$ at $4 \mathrm{ppm} 1195$, indicating the optimum concentration would be 2 to $4 \mathrm{ppm}$ Betz 1195. Both total and ortho phosphate increases with the use of $6 \mathrm{ppm}$ of Betz 1195 (Figure 15).

\subsection{DISCUSSION AND CONCLUSIONS}

The zeta potential data suggests the following adsorption process occurs in silica removal. Through the addition of magnesium chloride and pH adjustment with either lime or caustic, magnesium hydroxide is formed. There is adsorption between the magnesium hydroxide and the silica. With the addition of calcium ion as either lime or calcium chloride, there is a bridging type adsorption between the calcium and the silica magnesium hydroxide particles.

The adsorption process is favored by the following observations: 


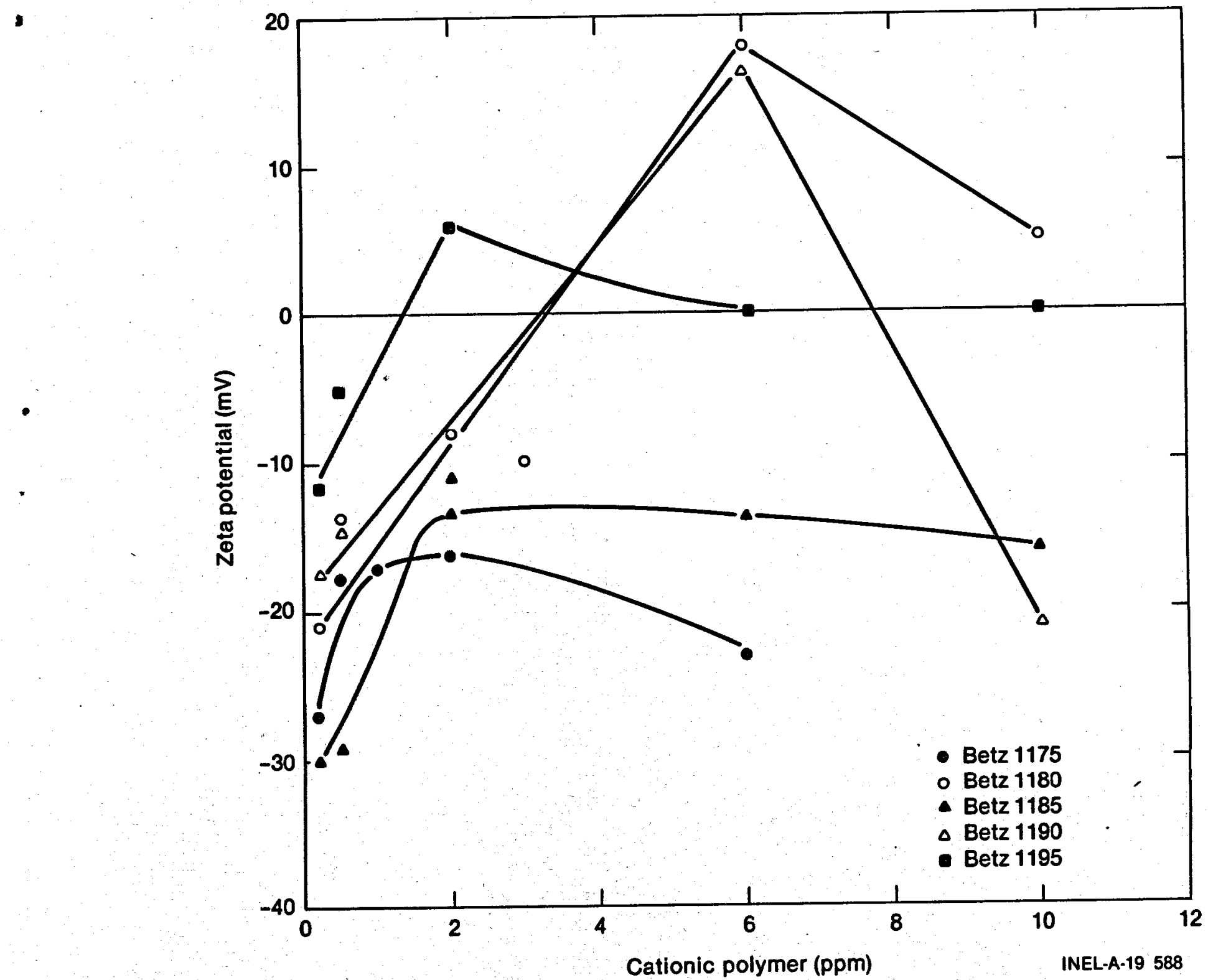

Figure 12. Zeta Potential of the Iron-Phosphate System as a Function of Cationic Polymer 


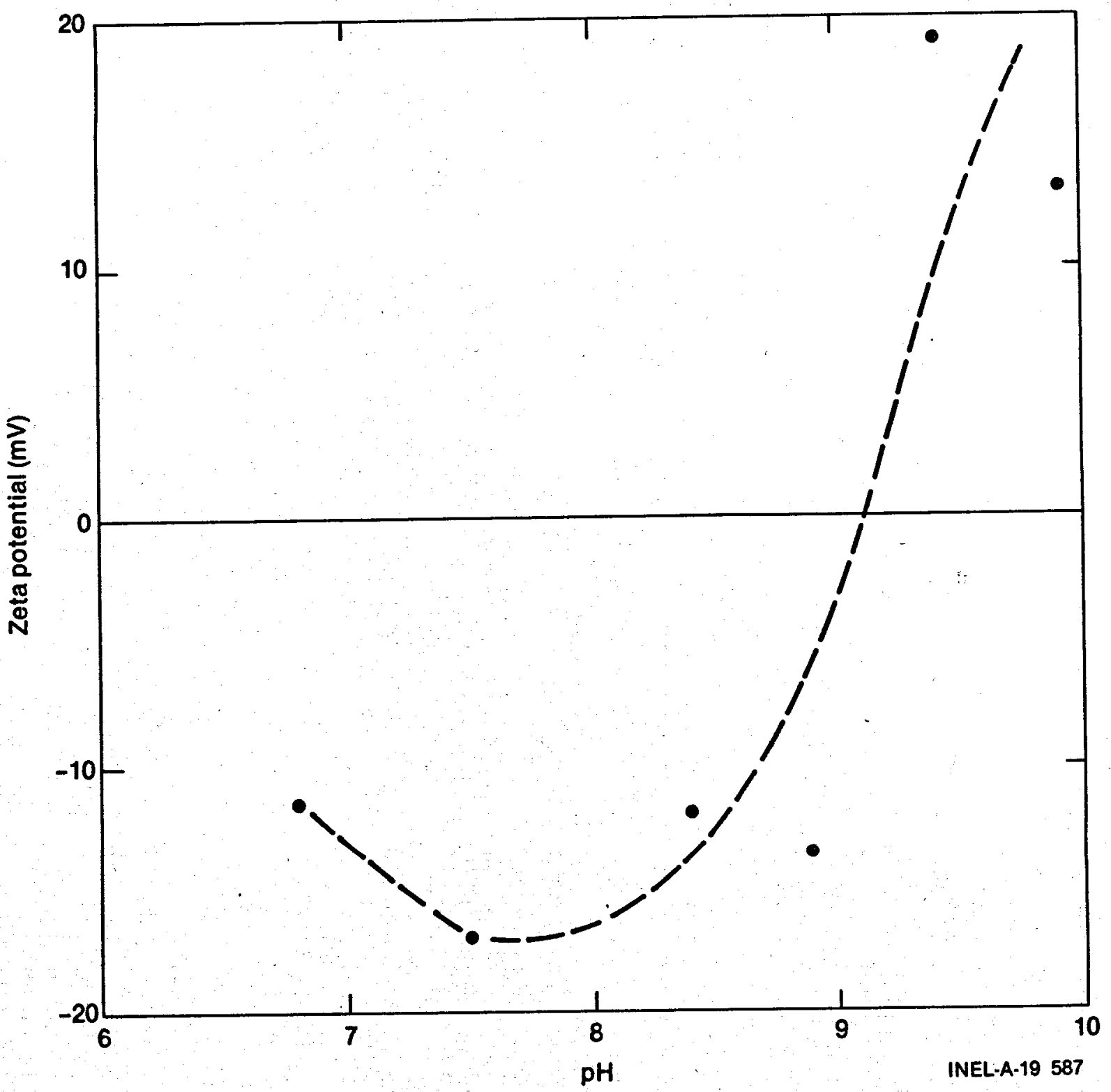

Figure 13. Zeta Potential of the Iron-Phosphate System with $2 \mathrm{ppm}$ Betz 1195 as a Function of $\mathrm{pH}$ 


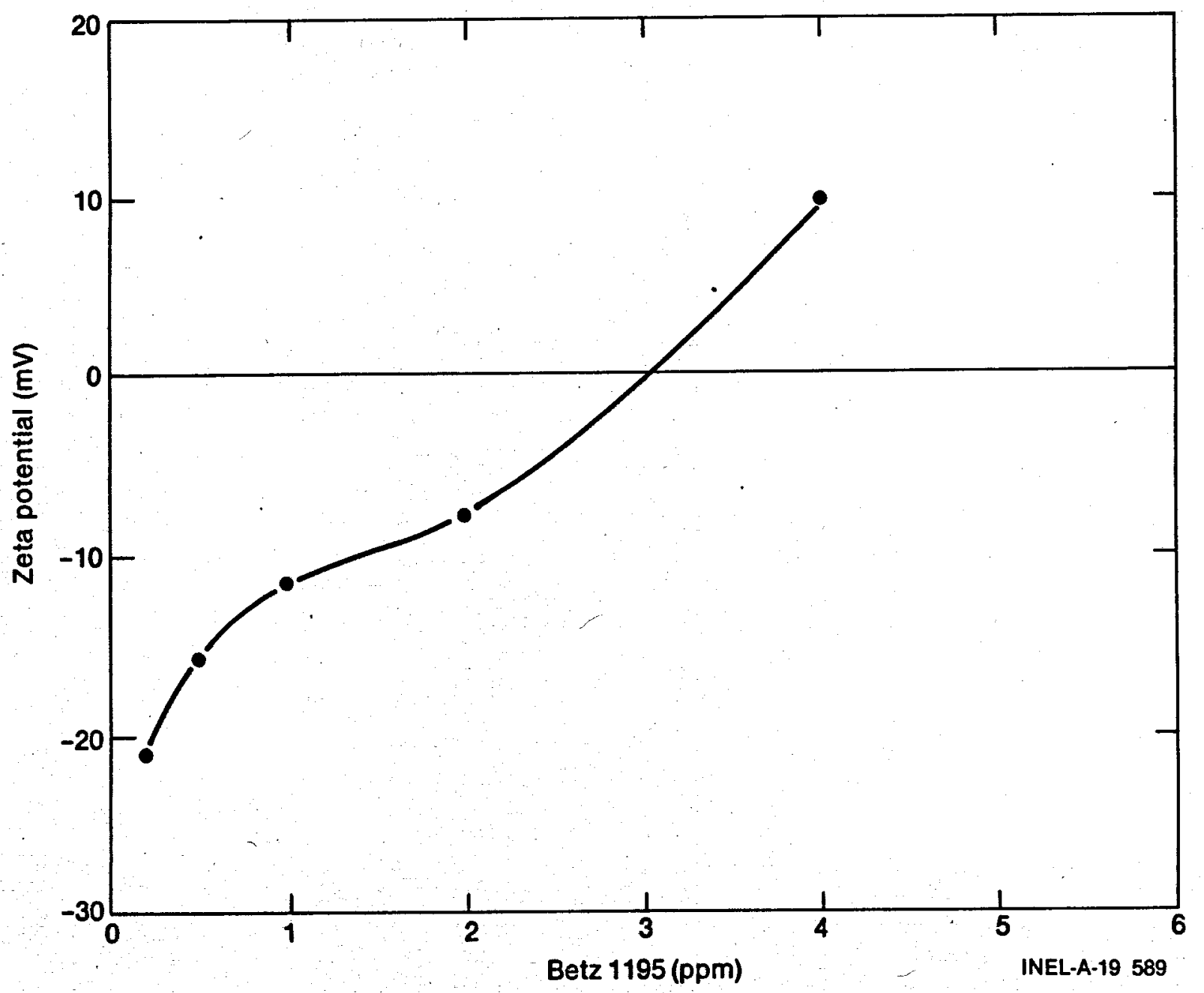

Figure 14. Zeta Potential of the Iron-Phosphate System at pH 9.2 as a Function of Betz 1195 Concentration 


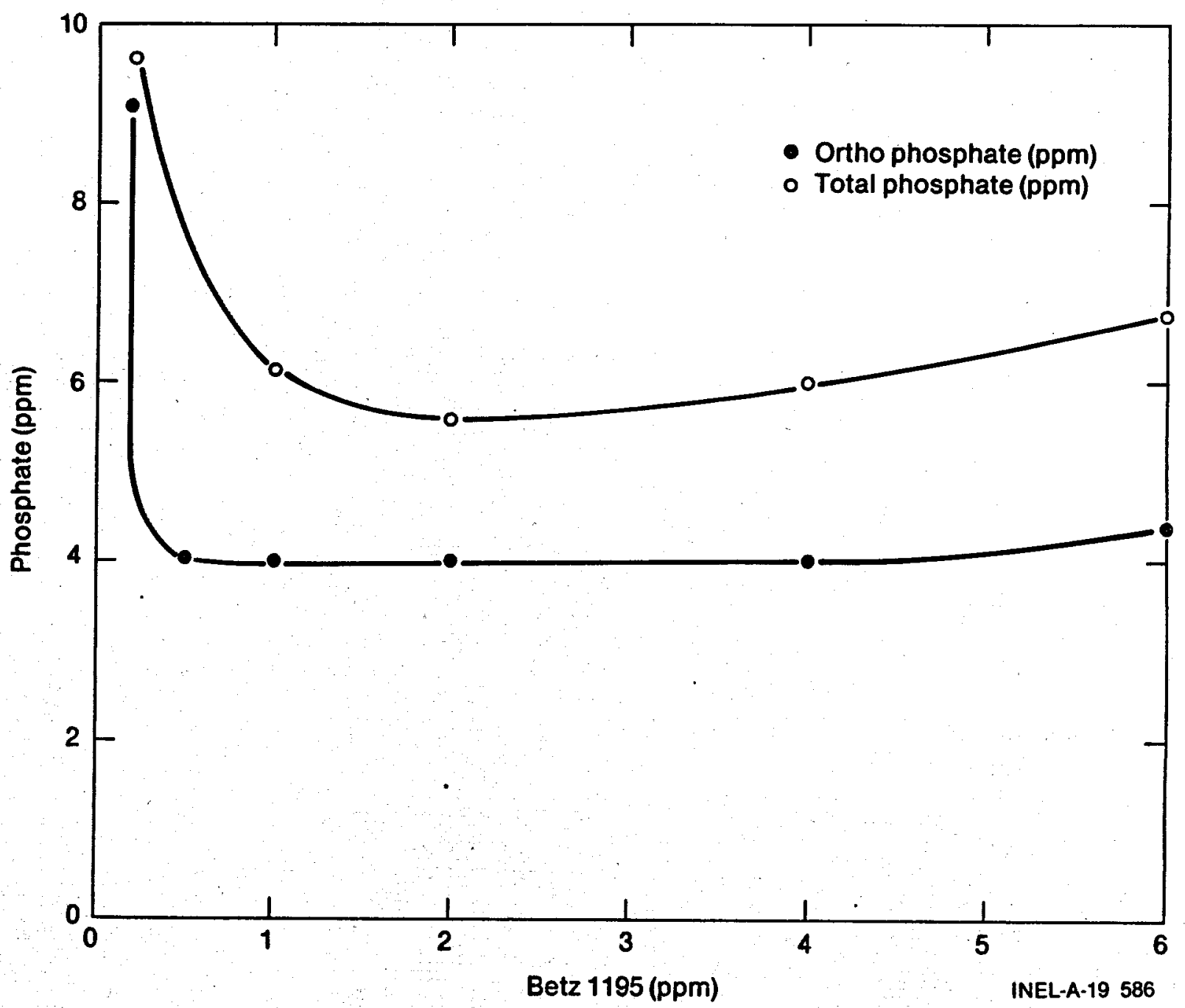

Figure 15. Total and Ortho-Phosphate Remaining in the Solution at pH 9.2 as a Function of Betz 1195 Concentration 
1. The addition of magnesium or calcium ion without $\mathrm{pH}$ adjustment causes a small positive increase in the zeta potential indicating a weak adsorption.

2. The addition of lime without magnesium present causes a large positive increase in the zeta potential. This is due to the adsorption of the calcium onto the negative silica - the formation of a salt; however, with this adsorption, there is little coagulation or settling of the silica.

3. When $300 \mathrm{ppm}$ of magnesium oxide is added to the geothermal water prior to $\mathrm{pH}$ adjustment with lime, the zeta potential becomes positive. In addition, there is a linear decrease in the silica concentration.

4. When $300 \mathrm{ppm}$ of magnesium oxide is added to the geothermal prior to $\mathrm{pH}$ adjustment with caustic, the zeta potential becomes increasingly more negative. This is probably due to the adsorption of the hydroxide onto the silica magnesium particle. If the sodium is adsorbed, the adsorption causes little change in the zeta potential.

5. With $300 \mathrm{ppm}$ magnesium oxide present, the addition of calcium chloride causes little change in the zeta potential with no $\mathrm{pH}$ adjustment.

6. With $300 \mathrm{ppm}$ magnesium oxide present, and the $\mathrm{pH}$ adjusted to 10.2 with caustic, the zeta potential becomes increasingly more positive with calcium addition.

7. When $300 \mathrm{ppm}$ of magnesium oxide is added to deionized water, the zeta potential shows a general tendency to become more negative as a function of $\mathrm{pH}$ when lime is used for $\mathrm{pH}$ adjustment.

Polyelectrolyte adsorption appears to be due to the chemical adsorption of the anionic polyelectrolyte onto the now positive silica complex. Optimum silica reduction is obtained between one and eight ppm of Betz 1125L; however, 
other data indicate a significant amount of scatter in silica concentration and zeta potential at eight ppm of the polyelectrolyte. At $0.2 \mathrm{ppm}$ of polyelectrolyte, there is still a reduction in silica.

The zeta potential study of the phosphate reduction system, using ferrous sulfate, indicated the optimum reduction occurred at approximately $30 \mathrm{ppm}$ of iron. Using $30 \mathrm{ppm}$ of iron and lime for $\mathrm{pH}$ adjustment, the iron-phosphate particle becomes positive after $\mathrm{pH}$ 11.5. Betz $1125 \mathrm{~L}$ is much more effective at $\mathrm{pH} 11.7$ than 11.0 with the optimum reduction occurring at 1 to $2 \mathrm{ppm}$ of 1125L. Use of a cationic polymer results in operation at a much lower pH. Of the 5 cationic polymers used, Betz 1195 showed a more stable $\mathrm{pH}$ curve with the optimum $\mathrm{pH}$ being 9.2 adjusted with lime and the optimum polymer concentration being 2 to 4 ppm of Betz 1195.

\subsection{RECOMMENDATIONS}

The zeta potential data and silica concentrations indicate an optimum MgO concentration, added as $\mathrm{MgCl}_{2}$, is between 150 and $250 \mathrm{ppm}$ of $\mathrm{MgO}$. This is substantially lower than the recommended $450 \mathrm{ppm}$ of $\mathrm{MgO}$. This recommendation was based on previous work (Suciu and Wikoff), in which conditions were more harsh. The cost reduction, such a reduction in $\mathrm{MgO}$ concentration would result in, as outlined below:

TABLE 2. COMPARISON OF COST WITH REQUIRED MgO CONCENTRATION

\begin{tabular}{cr}
$M g 0(\mathrm{ppm})$ & $\$ /$ year \\
\hline & \\
150 & 57,000 \\
250 & 94,000 \\
450 & 138,000
\end{tabular}

The optimum polyelectrolyte concentration, as indicated by the data, lies between one and eight ppm of Betz 1125L. The lower concentration is recommended due to the increased silica concentration sometimes obtained at the upper range while obtaining the data. Depending on the end silica concentration desired, the 
data indicates that even with $0.2 \mathrm{ppm}$ of the polyelectrolyte silica is less than two ppm. Betz Corporation recommended a concentration of four ppm. The data here indicates that a concentration of one ppm will result in the same reduction. The cost reduction is outlined below:

TABLE 3. COMPARISON OF COST WITH REQUIRED POLYELECTROLYTE CONCENTRATION

\begin{tabular}{cr} 
Polyelectrolyte $(\mathrm{ppm})$ & $\$ /$ year \\
\hline & \\
0.2 & 260 \\
1.0 & 1,220 \\
2.0 & 2,450 \\
4.0 & 4,980
\end{tabular}

The zeta potential study for the iron-phosphate system indicates the optimum iron concentration lies between 20 and $30 \mathrm{ppm}$ iron. The optimum $\mathrm{pH}$ using the cationic polymer, Betz 1195, is 9.2 with the $\mathrm{pH}$ being adjusted with lime. Optimum polymer concentration is 2 to $4 \mathrm{ppm}$ of Betz 1195 . Further optimization will result from the operation of the phosphate reduction system since the zeta potential study has only looked at the iron-phosphate particle in domestic water. Dispersants as well as zinc sulfate will be present in the blowdown water. The zeta potential will be examined again when the blowdown system is operating.

Although the zeta potential study gives some starting concentration for the magnesium oxide, Betz 1125L, iron, and Betz 1195, further optimization should result from the operation of the plant since other elements may play a role there in determining the surface chemistry, and consequently, the necessary concentrations. 


\subsection{REFERENCES}

1. Suciu, D. F., and Miller, R. L., Removal of Silica From Raft River Geothermal Water, EGG-FM-5170, June 1980.

2. Adamoon, Arthur W., Physical Chemistry of Surfaces, 2nd Edition, John Wiley and Sons, Inc., New York, New York, 1967, pp. 209-225.

3. Zeta-Meter Manual ZM-80, Zeta-Meter, Inc., New York, New York, 1980.

4. Hanna, H. S., and Somasundarin, P., "Flotation of Salt Type Minerals," Flotation, American Institute of Mining, Metallurgical, and Petroleum Engineers, Inc., Vol. 1, New York, 1976.

5. Riddick, Thomas M., Control of Colloid Stability Through Zeta Potential, Zeta-Meter, Inc., New York, New York, 1968.

6. Slater, R. W., Clark, J. P., and Kitchener, J. A., "1-Chemical Factors in the Flocculation of Mineral Slurries with Polymeric Flocculants," Brit. Ceramic Soc. (Clays and Other Colloid Systems), 13, June 1969, pp. 1-12.

7. Suciu, D. F., and Wikoff, P. M., Corrosion Testing of Carbon Steel in Aerated Geothermal Brine, EGG-GTH-5474, February 1981. 